\title{
L'evolució de les bèsties. A propòsit del Bestiari de Pere Quart i les Histoires naturelles de Jules Renard
}

\author{
The evolution of the beasts. \\ About Pere Quart's Bestiary \\ and Jules Renard's Histoires naturelles
}

\author{
Jordi Malé \\ Universitat de Lleida \\ jordi.male@udl.cat
}

\begin{abstract}
This paper has two aims: on the one hand, to compare Joan Oliver's Bestiari with works such as Bestiaire ou cortège d'Orphée by Guillaume Apollinaire (1911), "Bestiario" by Ramón del Valle-Inclán (in La Pipa de Kif, 1919), The animaux et leurs hommes. The hommes et leurs animaux by Paul Éluard (1920) and, above all, Histoires naturelles by Jules Renard (1896), in search of possible influences and coincidences. The other aim is to classify and analyze the poems in order to clarify the intention with which Oliver wrote the Bestiari and to relate it to the didactic and moral purpose of medieval Bestiaries and ancient Fables.
\end{abstract}

Keywords: Joan Oliver, Jules Renard, Bestiaries, comparative literature, poetry

\section{ORIGEN DEL BESTIARI DE PERE QUART}

Poc després de l'esclat de la Guerra Civil, i amb un llibre poètic ja editat (Les decapitacions, 1934), Joan Oliver escrivia 1" "Oda a Barcelona", datada el mes d'agost de 1936 i publicada pel setmanari Mirador el 19 de novembre ${ }^{1}$. Setmanes abans

${ }^{1}$ La tornaria a publicar el juliol de 1937 a Hora de España, VII, que és on consta la data (Turull, 1984, p. 49). També la va publicar, en un full plegat, el Comissariat de Propaganda de la Generalitat de Catalunya, però no hi consta la data. 
d'acabar l'oda, va aparèixer a la premsa la convocatòria del premi de poesia Joaquim Folguera, on s'indicava que el termini per presentar-hi obres era el dia 23 d'octubre (Redacció, 1936a, p. 16). Oliver hi concorreria amb Bestiari, llibre de poemes que obtindria el guardó el 21 de desembre (Redacció, 1936b, p. 6) i que seria publicat a mitjan 1937 pel Departament de Cultura de la Generalitat, amb il·lustracions de Xavier Nogués².

Desconeixem la data de redacció del Bestiari. Tractant-se de poemes en general breus (dels quaranta-sis, n'hi ha vint-i-cinc que no passen dels sis versos), no es pot descartar que Oliver els escrivís durant els primers mesos de la guerra; és segur, en qualsevol cas, que hagué d'enllestir-los i revisar-los poc abans del 23 d'octubre del $36^{3}$.

També desconeixem les raons que el van dur a compondre un bestiari; o precisant-ho més: a compondre el primer bestiari en vers de la literatura catalana. Perquè d'aplecs de textos en prosa dedicats a animals ja en trobem -com és ben sabut-des de l'època medieval, amb els també anomenats Bestiaris, uns plecs de manuscrits dels s. XIV-XVI que no duen pròpiament aquest títol i la majoria dels quals són versions catalanes del Bestiario toscano (s. XIII). Malgrat que aquests textos no s'editarien fins als anys 1963-1964, Ramon d'Alòs-Moner els va donar a conèixer el 1924 en un discurs a la Reial Acadèmia de Bones Lletres de Barcelona, titulat "Els bestiaris a Catalunya" i publicat aquell mateix any. No es coneixen, d'altra banda, obres catalanes d'aquest tipus al llarg dels segles XVII, XVIII i XIX. I malgrat que al tombant i a principis del segle

\footnotetext{
${ }^{2}$ Sobre el Bestiari, vegeu Turull (1984, p. 37-48), Balaguer (2007) i Carbó (2016), que proposen plantejaments diferents al del present article (malgrat puguin coincidir en la interpretació d'alguns aspectes de l'obra). L'article de Balaguer, per exemple, parteix de la tesi que "la literatura el que ens exposa són les incògnites que la humanitat es planteja, les seves pors, els seus desconeixements i els procediments a través dels quals tendeix a explicar-los o a resoldre'ls" (2007, p. 166); una tesi que suposa assumida per Oliver, el qual al Bestiari "el que fa es plantejar-se les implicacions que en una certa representació de les relacions home-realitat suposen els usos literaris i d'altres ordres que fem dels animals" (2007, p. 168). El present article, en canvi, més que no pas aquesta qüestió de la representació literària -se la plantegés o no Oliver (remetem el lector a l'article de Josep M. Balaguer)-, vol intentar mostrar la diversitat de tipus de poemes inclosos al Bestiari centrant-se en alguns dels recursos emprats pel poeta, i també pretén explicar el tractament que es dona a les bèsties dins l'obra fent-ne una lectura des de la literatura comparada i també en clau biogràfica.

${ }^{3}$ El fet que Oliver situï abans el Bestiari que 1"“Oda a Barcelona" dins els diversos aplecs de la seva obra poètica obeeix, de ben segur, a raons d'organització de la seva producció, perquè el Bestiari guarda estreta relació literària amb Les decapitacions (1934), mentre que 1'“Oda", pel fet de tractar de la guerra, fa de transició cap a les obres publicades a la postguerra. Si es considera, d'altra banda, que l'obra presentada al Premi Folguera 1934 (que es va resoldre a principis de 1935) amb el títol Les decapitacions i signada amb les inicials N. N. (potser com a facècia) (Redacció, 1935a, p. 6) és el llibre d'Oliver ja editat (al premi, s'hi podien presentar tant obres inèdites com publicades), durant el 1935 el nostre autor va escriure un altre aplec de poemes, titulat Poesia intima i presentat al Premi Folguera a finals d'aquell any sota les mateixes inicials N. N. (Redacció, 1935b, p. 11), que sembla que no s'ha conservat. El Bestiari, el va presentar signat amb el pseudònim Pere Quart i finalment li serviria per guanyar el premi.
} 
XX uns pocs escriptors van fer d'alguns animals el tema de les seves obres en prosa, cap es presentava com un bestiari ${ }^{4}$.

Pot afirmar-se, doncs, que Oliver va dur a terme el que Gérard Genette anomena una reactivació genèrica (1982, p. 287-291), en reprendre un gènere conreat segles enrere en la literatura catalana. Per bé que, seguint amb la terminologia de Genette, d'una banda, hi realitza una transformació formal, en versificar els textos (1982, p. 301); i, d'altra banda, una transformació semàntica, en actualitzar el marc diegètic en què es mouen les seves bèsties $i$ en adaptar-ne pragmàticament els comportaments per adequar-los a la intenció amb què estan escrits diversos dels poemes, com veurem més avall (1982, p. 418).

La singularitat més rellevant del Bestiari d'Oliver de 1936 rau en el fet -reiterem-ho- d'estar escrit en vers i ser el primer bestiari poètic català; tot i que, estrictament, no ho era del tot: poc abans l'Editorial Joventut havia publicat a Barcelona una Auca de les bèsties per a infants, amb il·lustracions signades per Lluís Macaya i Sanfeliu (1888-1953), que potser n'és també l'autor dels versos ${ }^{5}$. Les quartetes d'heptasíl·labs dedicades a cadascuna de les trenta-dues bèsties que l'integren són, això sí, d'escàs valor literari. Valgui com a exemple "El cavall": "El cavall és elegant / i no passa mai de moda, / per més que hom vagi inventant / nous vehicles amb la roda" (Macaya i Sanfeliu, 1935?, p. 12).

Més que no pas en aquesta auca, Oliver s'hauria pogut inspirar en alguns bestiaris poètics publicats en altres llengües a principis del segle $\mathrm{xx}$, com ara Le Bestiaire ou Cortège d'Orphée (1911), de Guillaume Apollinaire, amb petits poemes il·lustrats per Raoul Dufy; o l'inclòs com a secció, amb el títol de "Bestiario", dins La Pipa de Kif de Ramón M. del Valle-Inclán (1919); o en menor mesura, l'obra de tipus més avantguardista de Paul Éluard, Les animaux et leurs hommes. Les hommes et leurs $\operatorname{animaux}(1920)$.

Les imatges del Bestiari de Pere Quart i l'ús que el poeta hi fa del llenguatge són lluny, en general, dels poemes d'Éluard, plens de suggestions i d'apreciacions insòlites $^{6}$. L'obra d'Oliver, d'altra banda, res no té del plantejament mitologicosimbòlic del Bestiaire d'Apollinaire, centrat en la figura d'Orfeu, que és el jo poètic que parla en diversos dels poemes - mentre que, en altres, la veu és la del mateix poeta. Quasi totes les composicions d'aquest Bestiaire, la majoria integrades per una sola quarteta (que és l'estrofa més emprada per Oliver), fan referència a animals, si bé a vegades com

${ }^{4}$ El volum pòstum de Jacint Verdaguer Folklore (1907) contenia les obretes Què diuen los aucells? i Notes esparses (dedicades a bèsties diverses); Josep M. de Sagarra va publicar les proses d'Els ocells amics (1922), i uns anys després van aparèixer els relats de L'ós benemèrit i altres bèsties (1932), de Prudenci Bertrana. Vegeu Soldevila (1990).

${ }^{5}$ Tot i que el llibret no porta data, les altres obres infantils publicades per l'editorial que figuren en la 1lista del revers de la coberta són dels anys 1933, 1934 i 1935.

${ }^{6}$ Com ara al poema "Porc": "Du soleil sur le dos, du soleil sur le ventre, / La tête grosse et immobile, / Comme un canon, / Le porc travaille" (Éluard, 1920, p. 20). 
a pretext o terme de comparació per abordar altres temes, com ara l'amor ("La Puce", "La Chèvre du Thibet") o la poesia ("L’Éléphant", "La Chenille").

El "Bestiario" de Valle-Inclán, per la seva banda, inspirat en les visites de l'escriptor a la Casa de Fieras del parc madrileny del Buen Retiro, també difereix del de Pere Quart: les seves quartetes (de nou la mateixa estrofa) sobre diversos animals estan escrites amb la tècnica caricaturesca i expressionista de l'autor gallec, per bé que amb un ús de l'humor que, com el d'Oliver, no pretén riure's de les bèsties engabiades.

\section{EL BESTIARI I LES HISTOIRES NATURELLES DE JULES RENARD}

Respecte a l'humor, Jaume Bofill i Ferro assenyalava que el de Pere Quart era el resultat de l'“aliança de la bondat i l'esperit de crítica", i invocava, en aquest sentit, els noms de Dickens, Molière i "Jules Renard (tan pròxim al Pere Quart del Bestiari)" (1986, p. 226). Bofill pensava, indubtablement, en les Histoires naturelles (1896) de Renard. I va ser potser aquest bestiari literari, malgrat no en dugui el títol i estigui escrit en prosa, una de les referències d'Oliver a l'hora de compondre el seu.

Ja Domènec Guansé (sota el pseudònim "Begur" [1937]) havia esmentat l'obra de Renard en la ressenya que va dedicar al Bestiari de Pere Quart a La Publicitat el 18 de juny de 1937, però per assenyalar que "no s'[hi] assembla gens". Certament, són dos llibres ben diferents: el de Renard es compon de proses breus (n'hi ha d'una sola ratlla), algunes de les quals narratives i amb un cert caràcter autobiogràfic, mentre que el d'Oliver l'integren poemes que ell mateix qualificava, a la nota introductòria, de "poesia epigramàtica" $(56)^{7}$. La comparació entre ambdues obres, tanmateix, posa de manifest diverses similituds. Algunes en la forma, com ara l'ordenació dels textos seguint una certa classificació de les bèsties ${ }^{8}$. Però també n'hi ha en el fons.

D'entrada, reiterant l'apreciació de Bofill i Ferro, l'humor, vinculat amb diversos recursos literaris emprats per ambdós escriptors. Per exemple, l'associació metafòrica d'alguns animals amb altres realitats amb què guarden alguna similitud formal, però que resulten ben distants entre si -i és aquesta distància la que sovint genera l'humor-. "La Puce" de Renard, per exemple, esdevé "un grain de tabac à ressort" (Renard,

\footnotetext{
${ }^{7}$ Citaré sempre, indicant-ne només la pàgina, l'edició del Bestiari de Pere Quart inclosa en l'Obra poètica de 1999, que incorpora les darreres esmenes del poeta, les quals en general no són substancials respecte al text de la primera edició; quan convingui, això no obstant, assenyalaré els canvis entre versions.

${ }^{8}$ En el cas de les Histoires naturelles, hi trobem consecutivament "bèsties de corral, de fer bonic, de companyia, de prats i camps, de cria i de caça, arrossegadisses, saltadores, minses, rosegadores, de zoo i de bosc, aquàtiques [i] aèries" (Costa, 1999, p. 6). El Bestiari de Pere Quart s'ordena en mamífers del bosc, mamífers domèstics (amb la inclusió, entre l'Ase i el Cavall, de la Zebra en qualitat d'èquid), mamífers salvatges, ocells, rèptils, amfibis, peixos, insectes, aràcnids, mol·luscs i crustacis, fins a acabar amb un microorganisme unicel·lular i, finalment, el que seria un "vegetal" (ja veurem en quin sentit).
} 
1909, p. 75) $)^{9}$. Oliver, per la seva banda, converteix 1'“Ostra" en un "gargall de sirena"; i no s'oblida de transformar també la conquilla: "Àdhuc tapadora / té per higiene / cada escopidora" (104).

Aquest registre humorístic de ressonàncies una mica grolleres pel "gargall", bé que atenuades per la "sirena" que 1'“escup", Oliver l'empra més aviat poc dins el Bestiari, talment com apareix de forma esporàdica en les proses de Renard (Autrand, 1978, p. 210). Ben altrament, l'autor francès a vegades se serveix d'imatges ben plàstiques per a les seves metaforitzacions, que fins tenen un punt de lirisme; com a "Le Papillon": "Ce billet doux plié en deux cherche une adresse de fleur" (75). Algunes de les imatges de Pere Quart són també de gran plasticitat, com la del poema "Cérvol": "Com un arbre rabent, / arrelat dins el vent..." (57); en aquest dístic, la bèstia i la seva cornamenta s'associen amb un arbre capgirat que tindria al capdamunt les arrels inserides dins l'aire, tot connotant, així, la idea de moviment, en contraposició a la naturalesa estàtica de la planta ${ }^{10}$.

En algun cas, Renard transforma simplement una part o un aspecte de l'animal, com a "L’Écureuil": "Du panache! du panache! oui, sans doute; mais, mon petit ami, ce n'est pas là que ça se met" (75); en aquesta prosa, l'autor s'adreça directament a l'esquirol advertint-li que el plomall (en què ha convertit la seva gran cua) és al cap que hauria de dur-lo (talment l'adorn d'un barret). Pere Quart fa el mateix a "Zebra": transforma en una peça de vestir un element de la bèstia (les ratlles de la pell) i se li adreça per fer-li una divertida remarca sobre el seu "vestuari": "Pel desert corre la brama / que no et saps treure el pijama" (62).

"Elefant" és un altre dels poemes en què Oliver transforma imaginativament parts d'una bèstia: "De la trompa grisa / canons acerats, / de les quatre potes / de temple pilars, / popular bandera / de l'orella gran, / de la pell gruixuda / galtes d'advocat, / dels ullals de vori / torres de pedant" (70). La forma en què està escrit aquest poema recorda una mica aquelles endevinalles populars en què, per velar un objecte, se'n metaforitzen algunes parts; com ara la següent: "Tinc la panxa grossa, / la boca molt ampla, / el ventre m'omplenen / de sucs i viandes; / tinc dues orelles / que's per'llà on m'agafen, / i el seient em cremen / per a utilitzar-me" (Millà, 1988, p. 142). Mentre que al poema de Pere Quart es transformen parts de la bèstia en objectes (a banda de les galtes d'advocat), en aquesta endevinalla referida a una olla les parts d'aquest estri són convertides en les d'un organisme animal ${ }^{11}$.

Dins l'obra trobem altres poemes que fan servir alguns dels recursos característics de les endevinalles, com ara "Os blanc": "Batia el sol / damunt el gel. / Aquell os blanc

\footnotetext{
${ }^{9}$ Citaré sempre l'última edició de les Histoires naturelles publicada en vida de l'autor francès (la cinquena, de 1909).

${ }^{10} \mathrm{~A}$ “Tortuga" (87), la imatge del rèptil és associada amb la d'un guerrer antic que, caigut en combat i parapetat sota el seu escut, fuig arrossegant-se lentament. És l'únic poema del llibre en què la bèstia no és la protagonista o el tema dels versos, sinó sols el segon terme d'una comparació.

${ }^{11}$ Sobre els mecanismes de les endevinalles, vegeu Oriol (2002, p. 94-97).
} 
/ era un os negre" (68); per al-ludir a l'ombra de l'animal projectada pel sol sobre el glaç s'afirma que la bèstia és alhora de dos colors contraposats, talment l'objecte d'aquesta endevinalla: "Una colometa, / que és negra i és blanca; / sense ales, vola; sense llengua, parla", en referència a una carta (Millà, 1988, p. 61-62).

Fins i tot un dels poemes del Bestiari, "Camell i dromedari", està escrit amb la forma interrogativa característica de moltes endevinalles: "¿És el dromedari / o el camell, senyors? / ¿Quin, de l'un o l'altre, / té un gep o en té dos?" (65). Val a dir, però, que no es tracta de cap endevinalla enginyosa basada en un joc lingüístic o semàntic, sinó que és l'expressió d'un dubte ben corrent entre la gent. Tampoc els altres poemes que hem vist suara no són pròpiament endevinalles, però tots estan escrits amb el mateix esperit lúdic d'aquestes. Un esperit característic de bona part de la poesia de Pere Quart, el qual, al pròleg a Poesia empírica (1981), considerava "el joc com un element importantíssim en la vida dels homes, éssers juganers per naturalesa, tant com els animals dits inferiors. [...] Per això mai no he deixat d'escriure versos simplement jocosos" (Pere Quart, 1999, p. 927). No pot sorprendre de trobar aquesta intenció juganera en una obra com Bestiari, dedicada justament a aquests "animals dits inferiors".

L'esperit lúdic també és present en uns quant poemes construïts mitjançant jocs de paraules. Com ara "Bacallà": "La tempesta esqueixà / un banc de bacallà" (93); el poeta usa el verb "esqueixar" per designar el desgavell que la tempesta causa en una mola de bacallans, però aprofitant-ne les connotacions culinàries. O "Lluerna": "-Cuca de llum, ¿què cerqueu / pels marges amb la llanterna? / I diu ella sense veu: / -Una lluerna!" (96); aquí el poeta juga amb la sinonímia de "cuca de llum" i "lluerna" (que designen l'insecte Lampyris nocticula) i converteix en una diàfora la "lluerna" del darrer vers en relació amb la del títol, ja que la "lluerna" del poema el que cerca n'és una altra, de "lluerna", amb què aparellar-se i a la qual intenta atreure justament il·luminant-se (com si dugués una llanterna). En aquests versos, a més, hi ha també un joc fonètic per la semblança sonora entre "lluerna" i "llanterna".

Un dels poemes del Bestiari, "Bacil", és tot un joc de sons: "Ni / bri / bo: / mi- / cro- / bi" (106), amb totes les equivalències fòniques entre les seves síl labes ${ }^{12}$. I, alhora, és un joc visual perquè els seus versos monosíl labs disposats en columna recorden els bacils, que, vistos al microscopi, tenen forma de bastó (d'on ve el seu nom llatí, baculus).

La "jocositat", tanmateix, no sempre és deguda a jocs verbals. Alguns poemes tenen un humor més aviat conceptual, com "Girafa": "Tens el cap petit / perquè la distància / te l'ha empetitit" (72); la mida reduïda del cap d'aquesta bèstia en relació amb la còrpora, el poeta l'atribueix -humorísticament- a un fenomen visual: com que la distància empetiteix les coses que veiem de lluny, el cap s'hauria tornat petit pel fet d'estar tan allunyat del cos. També és conceptual l'humor dels versos finals de "Diplodocus" (88): el dinosaure hi parla com una espècie ja extingida, sols rescatada

${ }^{12}$ Vegeu l'anàlisi formal que en fa Joan A. Argente (1984, p. 48-50). 
de l'oblit pels estudiosos de la paleontologia que intenten reconstruir-ne l'esquelet; un animal que ell mateix, en no haver-se'n trobat la totalitat dels ossos, ja "no sap com fou bastit".

\section{LA HUMANITZACIÓ DE LES BÈSTIES I ELS BESTIARIS ANTICS}

És d'una altra mena l'humor de "Cap-grossos": "Acaben el segon curs / dels estudis de granota. / Ja els neix la tercera pota / i es fonen les cues llurs" (89); per referir-se a la seva metamorfosi, el poeta humanitza la bèstia en representar la seva transformació com el resultat d'haver estudiat per obtenir el "títol" de granota.

Aquest procés d'atribuir a les bèsties accions i comportaments humans, amb l'humorisme que se'n deriva, el trobem en altres poemes -i permet novament emparentar el Bestiari amb les Histoires naturelles de Renard, el qual l'utilitza sovint (com a "Dindes" o "L'oie", entre altres proses). L' "Hipopòtam" de Pere Quart, per exemple, resulta ser un animal capaç de riure's de si mateix: el seu gest característic d'obrir la boca de bat a bat esdevé una rialla provocada pel fet d'haver-se vist emmirallat a l'aigua i trobar-se lleig o ridícul -i d'aquí vindria la "ganyota" $(73)^{13}$. La "Coccinel-la" (o marieta) esdevé una jove excitada per l'arribada de la primavera ("quin dolç frenesí", "tota s'altera / la sang"), que la duu a fer bogeries ("El sol l'embriaga / li encén el magí"), com ara enfilar-se mà amunt fins a l'espatlla del poeta $i$, aleshores, saltar al buit, per anar a raure "al meu jardí" (101) ${ }^{14}$. El "Gripau" (91) és una bèstia que anhela escapar de la seva naturalesa -moviments lents i aspecte lleig- i somia que es transforma en un ocell que vola ben lleuger -un somni amb què "passa hores dolces" (91)-.

Hi ha un altre animal que també voldria ser una altra cosa: el "Bou", que aspira a fer-se poeta. El poeta humanitza, així, la bèstia, que s'imagina fent composicions bucòliques i èpiques; i alhora, inversament, bestialitza -diguem-ho així-1'obra humana que són els poemes, ara fets pel bou: les bucòliques tindrien "tàvecs i fems", i els herois de les epopeies serien "gent embanyada" que protagonitzaria "drames d'estable de banya doblada" (64) -en al·lusió a les banyes pròpies i a les de l'engany amorós-.

Dues altres bèsties són, encara, humanitzades: el "Porc" (60) se'ns presenta, parlant en estil directe, com si fos un home amb sobrepès que es planteja de començar a fer règim i practicar exercici per amagrir-se -i evitar, així, de ser sacrificat per Sant Martí. L'humorisme d'aquest poema contrasta amb el to dolgut amb què es plany, també en estil directe, la "Lloca" (83-84), que es veu a si mateixa com una dida seca,

\footnotetext{
${ }^{13}$ A la il·lustració de Nogués duu un llaç al coll per accentuar-ne la ridiculesa.

${ }^{14}$ La primera versió del poema acabava dient: “volà i no morí" (Pere Quart, 1937, p. 122), vers que reflectiria la sorpresa del poeta pel fet que la bestiola no cau a terra, com si desconegués que podia volar cal recordar que la marieta té les ales amagades sota els èlitres-, tot accentuant, així, el caràcter de bogeria de la seva acció. Deixo per a una altra avinentesa l'anàlisi de tot el joc metafòric entre la marieta, el robí (amb l'anell) i la sang, com també la dels mecanismes d'altres poemes.
} 
"eixuta de llet i d'amor", i com a "mare postissa" (li prengueren els ous propis i ha de cuidar polls que no són seus), la qual cosa la vexa i la fa objecte de befes per part dels altres animals.

Aquest procés d'humanitzar les bèsties és característic tant dels bestiaris medievals com de les faules antigues (Isop, La Fontaine, etc.). A l'Edat Mitjana, els bestiaris descrivien (sense cap rigor, és clar) els suposats comportaments d'alguns animals, reals o fabulosos; uns comportaments que, amb intenció exemplaritzant, aplicaven als humans per mostrar quins actes eren lloables i quins criticables ${ }^{15}$. Les faules, per la seva banda, humanitzaven directament les bèsties atribuint-los actituds humanes, sobretot vituperables (bé que no pas sempre), de la representació de les quals es volia extreure una lliçó moral.

En general, d'aquestes figuracions poc o molt literàries els animals en sortien malparats. Un fet que Oliver criticava i que atribuïa a una mena de venjança dels humans envers les bèsties des que, un cop creades per Jahvè, es desentengueren d'Adam -com s'apunta al Gènesi- $\mathrm{i}$ “es dispersaren alegrement per la selva, decidides a «viure llur vida»" (Oliver, 1999, p. 278). Ho declarava en un article inicialment publicat el juliol de 1967 a Serra d'Or i posteriorment titulat "Animals": "sembla que el punt més refinat de la campanya venjadora fou atès amb la invenció de les Faules: històries exemplars en les quals els humans simulen cínicament d'alliçonar-se ells mateixos servint-se de bèsties impecables a les quals són atribuïdes, sense cap fonament vàlid, les nostres preteses virtuts i, cosa encara més roïna, penjats els nostres vicis efectius i provats" (Oliver, 1999, p. 279).

El propòsit de Pere Quart al Bestiari es troba ben lluny del de les faules i els bestiaris antics ${ }^{16}$. Ni se'n pot extreure cap lliçó ni hi ha res de censurable en el comportament humanitzat amb què ens representa l"'Hipopòtam", la "Coccinel·la", el "Gripau", el "Bou", el "Porc" i la "Lloca". L'actitud del poeta envers les seves bèsties més aviat és d'empatia, o de pietat en el darrer cas. Fins i tot les dota, compassivament, d'un cert component de transcendència, com a "Peix mort", el qual té una "animeta" que va fins "als cels marins" (92) ${ }^{17}$. Dins el Bestiari només critica clarament les bèsties del poema "Mosques i mosquits", tot queixant-se que "la natura / diligent ens procura / una bèstia / per a cada molèstia" (97). I tan sols envers dos altres animals mostra un cert distanciament: el "Paó" (80), que metaforitza (amb la cua desplegada) en la "màgica aurora" d'un "paradís", però amb "el cel postís" (un adjectiu que degrada la imatge esplendorosa inicial tot connotant una aparença enganyadora); i la "Garsa", de qui ridiculitza

${ }^{15}$ Val a dir que de vegades és en relació amb Déu que es descrivien les actituds de les bèsties, que aleshores eren lloables, és clar.

${ }^{16}$ També Balaguer (2007, p. 168) n'assenyala el distanciament.

${ }^{17}$ El poeta imagina el cel marí com un mar capgirat, de manera que l'obscur fons marí, on se suposava que ja no hi ha vida (amb les restes dels vaixells naufragats), en seria el sostre, la part de més amunt, i l'ànima aniria encara més enllà. Oliver al·ludeix a l'ànima dels animals dins Temps, records (Oliver, 1999, p. 224). 
l'actitud de posar-se a xisclar en veure el caçador i fugir-ne, quan no és un ocell que sigui objecte de caça (per bé que ella no ho sap). L'aparença vistosa d'ambdues aus i que no siguin víctimes dels caçadors -tornarem sobre aquesta qüestió- són factors que devien contribuir a la poca afecció que el poeta mostra envers elles ${ }^{18}$.

Dins el Bestiari hi ha dos altres animals, d'altra banda, que tradicionalment són vistos de manera negativa: la "Ratapinyada" (74) i el "Serpent" (86). Són les dues úniques bèsties que Pere Quart presenta en situacions fora de la realitat: la ratapinyada, en relació amb les contarelles de bruixeria i superstició (amb humor); i el serpent, en relació amb el relat bíblic del Gènesi (sense humor i veient-lo com una encarnació del mal).

Llevat d'aquests casos, l'actitud d'Oliver cap a les seves bèsties és -reiterem-hod'empatia. I en consonància amb la seva oposició a les faules, evita de mostrar-les assumint mals capteniments humans. Només ho fa en dos casos: el "Musclo" acaba mort i "enterrat" dins una paella "de tant beure a doble queix" (a l'edició de 1937, però, el mol·lusc no tenia el vici de la beguda, sinó que simplement "Visqué sol, sense salut. / Portà dol de si mateix" [127]); el "Pregadeu", per la seva banda, és transformat en una "monja" que resa per alleujar "de pecats el món", uns pecats humans assimilats als quefers ben innocents de les bèsties, com "la formiga / que agavella avarament", "el mal escarabat / que amb sutzura fa mercat" (100), etc.

\section{UNA POESIA AMB ESPERIT CRÍTIC}

La majoria de vegades, en contrast, és cap als mateixos humans que el poeta adreça la innegable intenció crítica d'alguns dels poemes -remarcada per Bofill i Ferro-; i, per no carregar-ne el pes - per no dir el mort-als animals, fa que també homes i dones apareguin dins els versos.

De vegades és una crítica indirecta i bonhomiosa, feta amb un somriure, com a "Granotes", en què ens presenta uns infants que es burlen de les que veuen en un bassiol perquè "No saben el crawl" (90) - o sigui: jutgen indegudament els moviments de les granotes, del tot adequats a les necessitats pròpies, en considerar-los en relació amb l'estil de nedar que s'anava popularitzant d'ençà dels anys vint.

A "Pingüí", ens representa l'animal, amb els seus colors negre i blanc, com si anés vestit amb frac i armilla; però en destacar que conserva "el decòrum que ens manca" (85), es riu de l'aparença de les persones a la platja, amb els seus banyadors gens de-

${ }^{18}$ Val a dir que la naturalesa del paó l'ha fet objecte, al llarg dels segles, d'un tractament semblant al que trobem en el poema de Pere Quart. Apollinaire el presentava tot bell en desplegar la cua, "Mais se découbre le derrière" (1997, p. [57]) -una observació que treia del Tresor de Brunetto Latini (s. XIII). Quant a la garsa, Renard deia que és una bèstia "si dédaignée" -cal sobreentendre que pels caçadors"qu'elle semble immortelle" i que, "insupportable avec sa queue-de-pie, c'est notre oiseau le plus français" (1909, p. 104). 
corosos a l'època. A "Arna", de qui es riu és dels poetes dels Jocs Florals, els premis dels quals (lliurats en cerimònies on calia anar mudat) depenien més de tenir "una amistat estreta" (98) amb el jurat que no de la qualitat dels poemes.

Els clergues són objecte de crítica a "Aranya" (102): aquesta bestiola, personificada, s'enamora d'una ampolla de vi del celler descrita amb "anques de senyora" (per la seva forma el-lipsoïdal, com les del vi de Francònia); i el fet que sigui un bisbe qui "dina" amb aquesta ampolla d'arrodonida aparença femenina seria una al·lusió a la lascívia del prelat-per això l'aranya voldria cobrir la nuesa de l'ampolla amb un vestit de teranyina-.

Les dones, d'altra banda, apareixen en dos poemes, i no en surten gaire airoses. A "Cranc" (105), el poeta constata que "l'amiga" calla quan, enmig de la gent, algú -talment un cranc- la pessiga; ara: és que voldria que ella denunciés l'acció o, més probablement, tan sols somriu maliciosament davant l'escena? A "Papagai" (78), compara els pocs mots que aconsegueix articular aquesta au amb els que diuen "qualques dames"; així, si l'ocell "parla" per un simple reflex mimètic, se sobreentén que aquelles dames, que semblen intel-ligents, de fet es limiten a repetir el que deuen haver sentit (el seu "seny", doncs, és una "ombra").

On més clarament es palesa l'actitud crítica del poeta davant certs comportaments dels humans i, alhora, la seva empatia envers els animals, és en un conjunt de poemes en què posa en primer terme justament el tracte que aquests reben per part d'aquells. Un tracte que forma part d'aquella "venjança" de què parlava Oliver a l'article "Animals": "I així les bèsties han estat i són perseguides, assassinades, sacrificades i escorxades; sotmeses a domesticitat, a esclavatge i a treball amb engany [...]; xollades i grollerament munyides i engreixades $[\ldots .$. ", sense oblidar "caceres i pesqueres, armes, paranys i esquers [...]; parcs zoològics, i circs [...]" -el memorial de greuges s'allarga fins a onze ratlles (Oliver, 1999, p. 278).

Tant la reclusió ("la reixa") com el maltractament ("les fuetades") dins el circ són al·ludits a "Tigre captiu" (69). L'“Ase" (61), per la seva banda, ens és presentat com una bèstia a la qual s'intenta sotmetre a "esclavatge i a treball"; el poeta admira la seva tossuda capacitat de resistència i critica l'home que el fustiga perquè, tot creient-se superior, en realitat no passa de ser un "ensuperbit esclau" (de les seves necessitats, limitacions, etc.). O un "paràsit", si considerem que el poeta al-ludeix al fustigador dins "Cavall", ja que la "mosca d'ase" que encabrita la dolça euga "branda fuet" (63). Cal remarcar que en cap d'aquests poemes no hi trobem ni un bri d'humor. Sí que n'hi ha, en canvi, però a causa del recurs de la humanització, a "Pollastret" (79), el qual seria una de les bèsties "sacrificades i escorxades", a la qual el poeta ha de dissuadir d'una fugida cap a França perquè encara hi és més apreciat gastronòmicament.

Entre les bèsties "grollerament munyides" destaca, és clar, la "Vaca suïssa"19, la qual, adreçant-se al seu munyidor en estil directe, es rebel·la contra la seva condició de

${ }^{19}$ Vegeu la lectura detallada que en fa Carbó (2016, p. 92-95) i també la de Joan A. Argente (1984, p. 48-50). 
bèstia sotmesa i explotada -en una humanització de nou humorística-. La possibilitat que el Bestiari fos escrit durant l'inici de la Guerra Civil permet fer una lectura política d'aquest poema: la referència a la trista "vaca cega" maragalliana al-ludiria al conformisme i la inacció del país al tombant i el principi de segle, que contrasta amb l'actitud de la vaca suïssa, que es revolta -com Guillem Tell es rebel·là contra el poder opressor-i no defuig la guerra, al·ludida amb la referència als militars: "qui s'acosti amb sabre!" (67).

També es fa al·lusió a la guerra, però ara sense humor, al poema "Xanguet", una de les bèsties víctimes de les "pesqueres". La visió d'un cuiner fregint-ne uns quants en una paella i fent-los girar enlaire (com mostra la il·lustració de Nogués) suggereix al poeta la imatge dels joves incorporats a l'exèrcit: "Volen peixos / marcials. / És de pànic / llur esguard: / són la lleva / d'aquest any"; i es compadeix del trist destí que els espera, talment el dels peixets, que seran pescats -"La nit d'aigua / els sobtarà" (95)- $\mathrm{i}$ cuits.

Cinc poemes, finalment, presenten bèsties que són víctimes de "caceres". Algunes, a més, per ser "escorxades". El poeta s'hi refereix a "Guineu" (59), en què, per censurar aquesta pràctica, capgira la situació i en lloc d'escorxar l'animal perquè una “cortesana" se'n faci un abric, planteja d'escorxar la dona perquè sigui la guineu qui n'aprofiti la pell. També a "Pantera" s'hi fa indirectament al·lusió en esmentar una catifa d"“adobada pell de fera" (71) que amorteix les petjades al seu damunt, talment les que fa amb sigil aquest felí.

Els altres tres poemes tracten de bèsties que són caçades i "sacrificades" per ser menjades, noves víctimes de la "venjança" dels humans. N'hi ha una, però, que se'n mig revenja: la "Griva fètida", que ha estat mortalment ferida pel caçador, el qual, però, no podrà cruspir-se-la perquè, mentre busca on ha caigut, l'au es dessagna i mor tot exhalant una forta fetor; i ho fa amb "punya retroactiva" -ens diu el poeta tot humanitzant l'ocell-i com a "pòstuma venjança" (82).

Per evitar que el "Colomí" també mori pels trets d'un caçador, el poeta l'insta a fugir: "No et paris, colomí blanc. / No paris blanc, colomí" -un altre poema basat en un joc de paraules, en aquest cas amb la diàfora de "blanc" (com a color i com a fitó)-. La preocupació del poeta, finalment, arriba també al "Conill": se li adreça perquè el veu intranquil, i la bèstia li expressa el seu temor que no vinguin els caçadors, els quals qualifica d"“homes de cor mesell" (58).

\section{OLIVER I RENARD DAVANT LES BÈSTIES}

Als darrers cinc poemes esmentats, l'actitud reprovadora del poeta envers els humans és força evident, especialment respecte als caçadors. I aquí torna a ser pertinent la comparació amb les Histoires naturelles de Renard. Tant l'autor francès com Oliver en la seva joventut van practicar la caça, $i$ tots dos esdevingueren uns caçadors penedits. El primer, en una de les històries del llibre ("Poissons"), declarava a través de M. Vernet, alter ego seu: "Un jour quelconque, à la chasse, après un de mes crimes, 
je me suis dit: de quel droit fais-tu ça? La réponse était toute prête. On s'aperçoit vite qu'il est répugnant de casser l'aile d'une perdrix, les pattes d'un lièvre. Le soir, j'ai pendu mon fusil qui ne tuera plus" (Renard, 1909, p. 88). Oliver, per la seva banda, a "D’una conversa amb Pere Quart" (1981), feia explicar al seu també alter ego: “Aquí Pere Quart s'estén sobre el seu interès pels cavalls i pels ocells, també pels conills, les llebres i les perdius, dels quals fa seixanta anys -mea culpa!- fou un perseguidor i un assassí sense entranyes" (Pere Quart, 1999, p. 926; vegeu també Oliver, 1999, p. 200).

Un altre punt de coincidència entre les Histoires naturelles i el Bestiari es troba en el fet que Renard va posar al final de la seva obra protagonitzada per animals -deixant de banda el text que clou el llibre i s'enllaça amb el que l'obre- una prosa sobre vegetals: "Une famille d'arbres". Oliver, per la seva banda, a la nota inicial de la seva obra deia que versava "sobre diverses bèsties i un vegetal" (Pere Quart, 1999, p. 56), $i$ al final hi va situar el poema "Jo". Tenint en compte que totes les altres composicions del Bestiari tracten d'animals, cal entendre que "Jo" és el vegetal?

Els primers versos -"Se m'arrapen conquilles a desdir, / creixen arreu de mi / molses estranyes. // He naufragat temps ha [...]" (107)-, juntament amb la il·lustració de Nogués, fan pensar en la cançó d'Ariel dins la segona escena del primer acte de $L a$ tempesta de Shakespeare: "Full fathom five thy father lies; / Of his bones are coral made; / Those are pearls that were his eyes [... $]^{\prime 20}$. En tots dos casos, els versos fan referència a un nàufrag el cos del qual, al fons de la mar ("al cul de sac de les antimuntanyes"), es va transformant en una mena d'organisme marí. Per aquí es començaria a entendre la relació entre "Jo" i un vegetal: no és que el poeta ho sigui, sinó que, en la seva situació de naufragat, és com si estigués vegetant, és a dir, com si dugués una existència passiva, sense emocions, sense activitat ${ }^{21}$. L'única cosa que espera és "la mà / enguantada de bus / que em desperti la pell i les entranyes" (107).

Quina mena de "naufragi" ha patit el poeta? La clau podria trobar-se en l'únic poema del Bestiari que encara no hem esmentat: "Rossinyol caduc" (77), escrit en forma de diàleg i protagonitzat per aquest ocell -humanitzat-, que tradicionalment s'associa amb la nit, l'amor i la poesia ${ }^{22}$. Tot i sentir-se vell i caduc, el rossinyol diu que encara refila impulsat per l'amor, que li és un consol, i experimenta sensacions agradables durant la nit (indirectament relacionables amb l'amor). La veu amb què dialoga, tanmateix, reiteradament vol dissuadir-lo de cantar i intenta desmentir el sentiment amorós que sembla impulsar l'ocell: perquè està sol (la soledat és atribuïda a la nit per hipàl·lage) $i$, consegüentment, aquelles sensacions agradables en realitat turmenten el cor (el pit per metonímia). Al final, l'ocell expressa amb vehemència el desig de sentir la passió amorosa: "Vull foc a l'entranya, / frisança a la pell!", però la veu li diu que s'enganya (que la nit, propícia als amants, l'enganya).

\footnotetext{
20 "A cinc braces sota aigua és el teu pare, / els ossos se li tornen de corall; / perles els seus ulls li esdevindran encara [...]" (Shakespeare, 1985, p. 41).

${ }^{21}$ Segons la darrera accepció de vegetar del DIEC2.

${ }^{22}$ Vegeu Gomis (1910, p. 370) i Manent (1934, p. 132-136).
} 
Aquests últims versos enllacen el poema amb "Jo", perquè el darrer desig expressat pel rossinyol és el mateix que voldria el poeta naufragat: aquest espera que el bus li "desperti la pell i les entranyes", i el rossinyol demana "foc a l'entranya" i "frisança a la pell". El "rossinyol caduc", doncs, seria el mateix poeta, el protagonista de "Jo"; i el naufragi del darrer poema (que el fa sentir com si vegetés) podria ser amorós, això és: un amor no correspost, amb el qual s'enganya a si mateix. Per això s'autoqualifica, al v. 5 de "Jo", de "sentimental il-lús". Desconeixem si de rerefons hi ha alguna experiència autobiogràfica. És un fet, això sí, que Oliver no es va casar amb la que seria la seva primera muller, Conxita Riera, fins al 1937, després de l'escriptura del llibre $i$ arran dels 38 anys, a una edat relativament avançada $i$ quan potser ja havia arribat a sentir-se vell i caduc ${ }^{23}$.

\section{A TALL DE CONCLUSIÓ}

"Jo", el darrer poema del Bestiari, queda deslligat de la resta, i la seva inclusió és una mostra de l'esperit lliure i trencador d'Oliver. Ell mateix admetia que havia escrit aquesta obra "sota el signe d'una inconfessable frivolitat" (56), i ho avalarien les composicions d'intenció més lúdica-com hem vist-, per bé que en contrast amb les que tenen una voluntat crítica envers els humans, com "Ase" o "Conill", o les d'un to greu i seriós, com "Lloca", "Rossinyol caduc" o "Jo". Un "jo" que també és present en altres poemes, només que sempre en relació amb les bèsties de què tracten. Perquè elles són el centre del llibre. Potser no podem respondre a la pregunta de per què Oliver es va decidir a compondre un Bestiari poètic, però és indubtable que, per raons diverses, sentia simpatia i empatia pels animals -també ho testimonia la dedicatòria del llibre: "Al Camús, el meu estimat gos" (56)-, i aquesta afecció el va dur a poetitzar-los bo i defugint el tractament literari que havien rebut en els bestiaris medievals i les antigues faules. Qui sap si aquesta obra insòlita no li va ser una vàlvula d'escapament en uns moments de crisi personal i també enmig del trasbals de la Guerra Civil. Només un testimoni o algun document autobiogràfic podrà aclarir-nos-ho algun dia.

\section{AGRAÏMENTS}

Aquest treball s'inscriu dins el projecte d'investigació del Ministerio de Ciencia e Innovación FFI2017-86542-P titulat La literatura de segundo grado: las relaciones hipertextuales en la literatura catalana desde el "Modernisme" hasta 1939. Més informació sobre l'activitat del grup investigador a: http://www.uv.es/ironialitcat/.

${ }^{23}$ L'any del casament, que no figura a les biografies del poeta, prové del web MyHeritage (2020), consultat el 6 d'octubre de 2020, on consta que "se casó con Conxita Riera Oliver Sallarès [...] (nacida Riera Sallarès) en 1937, a la edad de 37 años”. 


\section{REFERÈNCIES BIBLIOGRÀFIQUES}

Alòs-Moner, R. d' (1924). Discursos llegits en la "Real Academia de Buenas Letras" de Barcelona en la solemnial recepció pública de D. Ramon d'Alòs-Moner y de Dou el dia ler de juny de 1924. Barcelona: Imp. "Atlas Geográfico".

Apollinaire, G. (1997). Le Bestiaire ou Cortège d'Orphée. Tours: Bibliothèque de l'Image [Facsímil de la 1a edició, publicada el 1911].

Argente, J. A. (1984). De poètica i lingüistica. Vic: Eumo \& Edipoies.

Autrand, M. (1978). L'humour de Jules Renard. París: Libraire Klincksieck.

Balaguer, J. M. (2007). Pere Quart: Bestiari. Dins M. Baró, T. Colomer \& T. Mañà (eds.). El patrimoni de la imaginació: Llibres d'ahir per a lectors d'avui (p. 166-171). Palma: Institut d'Estudis Baleàrics.

Begur [pseud. de D. Guansé] (1937, 18 de juny). Un nou bestiari. La Publicitat, p. 1.

Bofill i Ferro, J. (1986). Poetes Catalans Moderns (ed. d’À. Susanna). Barcelona: Columna.

Carbó, F. (2016). Les primeres bèsties de Pere Quart. Rivista italiana di studi catalani, 6, 79-98.

Costa, J. (1999). Presentació. Dins J. Renard, Històries naturals (trad. de C. Costa-Woith; p. 5-11). Barcelona: Edicions de 1984.

Éluard, P. (1920). Les animaux et leurs hommes. Les hommes et leurs animaux. París: Au Sans Pareil.

Genette, G. (1982). Palimpsestes. La littérature au second degré. París: Seuil.

Gomis, C. (1910). Zoologia Popular Catalana. Barcelona: Tip. "L'Avenç".

Macaya i Sanfeliu, Ll. (1935?). Auca de les bèsties. Barcelona: Joventut.

Manent, M. (1934). Notes sobre literatura estrangera. Barcelona: Publicacions de "La Revista".

Millà (1988). 1.000 endevinalles catalanes amb les seves solucions. Barcelona: Millà.

MyHeritage (2020). Joan Oliver Turull. Recuperat de https://www.myheritage.es/names/joan_oliver\%20 turull.

Oliver, J. (1999). Obra en prosa. Barcelona: Proa.

Oriol, C. (2002). Introducció a l'etnopoètica. Valls: Cossetània.

Pere Quart (1937). Bestiari. Barcelona: Departament de Cultura de la Generalitat de Catalunya.

Pere Quart (1999). Obra poètica. Barcelona: Proa.

Redacció (1935a, 23 de gener). Llista de les obres presentades al "Premi Folguera 1934". La Veu de Catalunya, p. 6.

Redacció (1935b, 27 d'octubre). Els premis literaris de la Generalitat de Catalunya. La Veu de Catalunya, p. 11.

Redacció (1936a, 12 de juny). Els premis anuals de literatura, pintura i escultura de la Generalitat de Catalunya. La Veu de Catalunya, p. 16.

Redacció (1936b, 22 de desembre). El premi "Folguera" és atorgat a Joan Oliver. La Veu de Catalunya, p. 6.

Renard, J. (1909). Histoires naturelles (5a ed.). París: Arthème Fayard, Éditeur.

Shakespeare, W. (1985). La Tempesta (trad. de S. Oliva). Barcelona: Vicens-Vives.

Soldevila, L1. (1990). Estudi introductori. Dins P. Bertrana, J. Carner, P. Quart, Bestiaris (2a ed.; p. 7-23). Barcelona: Edicions 62.

Turull, A. (1984). Pere Quart, poeta del nostre temps. Barcelona: Edicions 62.

Valle-Inclán, R. del (2017). La Pipa de Kif. Madrid: Hiperión [Facsímil de la 1a edició, publicada el 1919]. 